\title{
Patient Delay and Stage of Diagnosis among Breast Cancer in Bangladesh
}

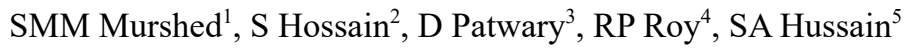

\begin{abstract}
:
Early diagnosis and prompt treatment is the principal goal of physicians dealing with breast cancer. In breast cancer care there are several causes of delay. Delay in diagnosis may be either patient or health provider originated. Besides there are no effective surveillance system, no nationwide active campaign for early diagnosis and screening. Hence delay in diagnosis is not unlikely. The study was done in a Cross sectional setting during January to December 2009 at the Department of Oncology of Bangabandhu Sheikh Mujib Medical University, Dhaka Medical College Hospital, National Institute of Cancer Research \& Hospital. A total 106 breast cancer patients were recruited for the study from the mentioned study places. Our data suggests on average 40 days delay from development of first symptom to attending traditional or unqualified provider. Time taken in transition from unqualified provider to qualified medical personnel was around another month. The time taken by medical personnel to establish the diagnosis through histopathology was around another $12.5 \pm 7.0$ days, thereafter to perform surgery after diagnosis it took $17.8 \pm 18.1$ days. After surgery another $31.05 \pm 33.8$ days were needed to start adjuvant chemotherapy or radiotherapy. Mean total time lapsed from appearance of symptom to perform surgery among breast cancer patients was $114.3 \pm 53.2$ days with a median delay of 117.5 days. Mean total time lapsed from appearance of symptom to have chemotherapy or radiotherapy among breast cancer patients was $151.2 \pm 62.8$ days with a median delay of 124 days. Regarding the cause of delay, in $53.8 \%$ cases, delay was resulted due to lack of awareness, in $38.9 \%$ cases delay was due to lack of money for treatment, in $7.5 \%$ case delay was due to the attempt to rely on alternative medicine, in $14.2 \%$ cases patients were reluctant, in $18 \%$ cases delay was due to problem in diagnosis. In $13.2 \%$ cases physician was treating the patient for other reason, in $36 \%$ cases patient herself made the delay for fear of consequences of disease or treatment and in $22 \%$ cases delay occurred due to long waiting period for surgery. In most cases delay resulted from multiple reasons. Patients with stages III \& IV were found to have significantly more total delay than stage I \& II diseases $(\mathrm{p}<.05)$. Patients with higher educated level made less delay than lower educated level. In conclusion, most important delay is caused by patient's own criteria and negligence. Awareness raising campaign may play an important role in reduction of the delay.
\end{abstract}

Key words: Delay, Patient, Breast cancer, Treatment, Bangladesh.

\section{Introduction:}

There is pessimism and stigma about cancer still prevailing in the society. Any delay in detection or treatment is considered to be important factor for $\operatorname{prognosis}^{1,2,3}$.

1.Dr. S. M. Munawar Murshed, MBBS, M-Phil (Radiotherapy), Assistant Professor, Department of Radiotherapy, Faridpur Medical College, Faridpur.

2. Dr. Syed Hossain, MBBS, M-Phil(Radiotherapy), Assistant Professor, Department of Radiotherapy, National Institute of Cancer Research \& Hospital, Mohakhali, Dhaka

3. Dr. Devasish Patwary, MBBS, M-Phil (Radiotherapy), Associate Professor, North East Medical College, Sylhet.

4. Dr. Ronoda Prosad Roy, MBBS, M-Phil (Radiotherapy), Assistant Professor, Department of Radiotherapy, National Institute of Cancer Research \& Hospital, Mohakhali, Dhaka.

5. Dr. Syed Akram Hussain, MBBS, FCPS (Radiotherapy), ExProfessor and Head, Department of Oncology, BSMMU, Dhaka.

Address of correspondence :

Dr. S. M. Munawar Murshed, MBBS, M-Phil (Radiotherapy),

Assistant Professor, Department of Radiotherapy, Faridpur Medical

College, Faridpur. Mobile: +88-01911-717474,

E-mail:smmurshed13@gmail.com
Breast cancer is the important health concern in many countries, and delaying in diagnosis and initiation of treatment is likely to result in tumour progression and a worse prognosis ${ }^{4}$. Prompt diagnosis and treatment of breast cancer provides best chance for long term survival. There are many reasons for women in Bangladesh wht they do not seek treatment for breast lump. Women not knowing where to find help when they discover a breast lump. Modern treatment options are not available in the communities. Women also report fear of the rejection by their friends and families if they are diagnosed with breast cancer ${ }^{5}$.

There are two common types of delay in diagnosis and treatment in breast cancer:

1. Patient delay: This covers the period from the first onset of symptoms to first medical consultation.

2. Provider delay: This covers from the first consultation to definite diagnosis or treatment ${ }^{5}$.

Delay occurs both before and after the women presented to General Practitioner. Women tended to 
delay because they assumed that their symptoms were not serious or were something other than cancer. Delay related to diagnosis was mostly due to diagnostic and administrative problems. Particularly difficulty worsens where doctors expected benign disease, where symptoms were not typical and where women had a previous history of benign breast disease ${ }^{6}$. Early detection and treatment is the key to survival in breast cancer. According to American Cancer Society (ACS), when detected at a localized stage 5-year survival rate is as high as $98 \%$, and for regional disease the rate is $86 \%$. If the cancer spreads to distant organs, 5-year survival drop to $26 \%^{7}$. The most important reasons for the lower survival rate in breast cancer in developing countries as compared with those of the developing countries is that they usually seek treatment at a more advanced stage of the disease ${ }^{8}$. Delay of more than three months is associated with lower survival ${ }^{3}$.

Time elapses (delay) between onset of symptoms and initial treatment for breast cancer results in presentation at a more advanced stage, with poorer survival ${ }^{8}$.

\section{Materials and Methods:}

The study was conducted in the department of Oncology Bangabandhu Sheikh Mujib Medical University, Department of Radiotherapy, Dhaka Medical College, National Institute of Cancer Research and Hospital, Mohakhali with patient histologically diagnosed of Breast Cancer. One hundred and six patients were included in the study after their written informed consent. Fifty eight percent $(58 \%)$ of them were new cases aged between 18 to 70 years. It was a cross sectional study from January to December 2009. Adenocarcinoma of breast cancer without brain metastasis, patients with Karnofsky Performance Status more than 70 were included. Patients with recurrent breast cancer, non epithelial cancer, patients not willing to participate and patients over 70 years of age were excluded from the study. The data were analyzed by using SPSS 16.

\section{Results:}

Most of the patients were in between 35 to 55 years of age (mean $40.6+5.9$ years) and were house wives. Ninety percent $(90 \%)$ of them were married. Among them $88 \%$ were Muslim.

Table I: Distribution of the respondents by Sociodemography.

\begin{tabular}{lll}
\hline Age & Frequency & Percent \\
\hline Less than 35 years & 19 & 17.9 \\
35 to 45 years & 74 & 69.8 \\
More than 45 years & 13 & 12.3 \\
Mean: 40.6 5.9 & & \\
Religion & & \\
Islam & 94 & 88.7 \\
Hinduism & 08 & 07.5 \\
Christianity & 04 & 03.8 \\
Occupation & & \\
Service & 08 & 07.5 \\
Housewife & 98 & 92.5 \\
Total & 106 & $\mathbf{1 0 0 . 0}$ \\
\hline
\end{tabular}

Among the respondents $69.8 \%$ were aged in between $35-45$ years, $92.5 \%$ of them were house wives (Table I).

Table II: Delay up to surgery and until receiving adjuvant chemotherapy or radiotherapy in different educational status in days.

\begin{tabular}{llrlll}
\hline & Education & $\mathbf{n}$ & Mean & SD & $\mathbf{p}$ \\
\hline $\begin{array}{l}\text { Delay up to } \\
\begin{array}{l}\text { surgery } \\
\text { Secondary and above }\end{array}\end{array}$ & 88 & 113.28 & 49.4 & 0.68 \\
& $\begin{array}{l}\text { Lowest through } \\
\text { Primary }\end{array}$ & 18 & 119.00 & 70.5 & \\
$\begin{array}{l}\text { Delay up to } \\
\begin{array}{l}\text { chemotherapy/ } \\
\text { Secondary and above }\end{array}\end{array}$ & 88 & 150.67 & 61.3 & \\
$\begin{array}{l}\text { radio therapy } \\
\text { Lowest through }\end{array}$ & & & & 0.87 \\
& Primary & 18 & 153.50 & 71.7 & \\
\hline
\end{tabular}

Among the patients $46(43.4 \%)$ went to village doctors, $12(11.3 \%)$ visited to Kobiraj, $10(9.4 \%)$ went to homeopath, 30(28.3\%) went to general practitioner and rest $8(4.6 \%)$ went to other care providers for seeking first health care for breast lump (Fig.1).

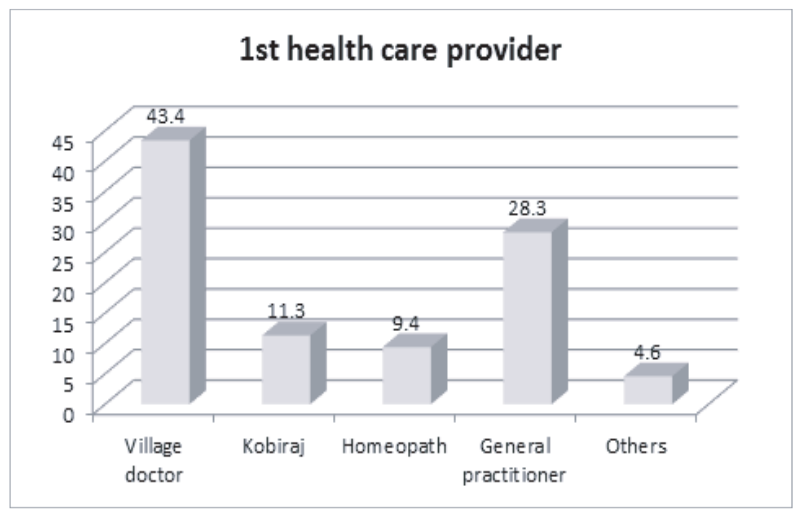

Figure 1: Distribution of the respondents by 1st health care provider

Table III shows the distribution of delay at different stages of health care seeking. Average delay occurred from development of first symptom to attending traditional or unqualified provider was $38.06 \pm 25.7$ days and median time lapsed was 35 days. The transition from unqualified provider to qualified medical personnel was $31.9 \pm 35.04$ days. The time taken by medical personnel to establish the diagnosis through histopathology was $12.5 \pm 7.0$ days thereafter to perform surgery after diagnosis it took $17.8 \pm 18.2$ days. After surgery another $31.05 \pm 33.9$ days were needed to start adjuvant chemotherapy or radiotherapy. 
Table III: Time elapsed at different steps of health care seeking (in days)

\begin{tabular}{lllllll}
\hline $\begin{array}{l}\text { Time elapsed from first } \\
\text { symptom to attending } \\
\text { medical care }\end{array}$ & \multicolumn{1}{c}{ Mean SD } & \multicolumn{5}{c}{ Median Min Max } \\
$\begin{array}{l}\text { From first symptom to } \\
\text { traditional or unqualified } 38.1\end{array}$ & \pm 25.7 & 35 & 11 & 90 \\
$\begin{array}{l}\text { provider } \\
\text { Unqualified provider to } \\
\text { medical personnel }\end{array}$ & 31.9 & \pm 35.05 & 25 & 7 & 180 \\
$\begin{array}{l}\text { Attending Medical } \\
\text { personnel up to histo } \\
\text { pathological diagnosis }\end{array}$ & 12.5 & \pm 7.0 & 19 & 5 & 30 \\
$\begin{array}{l}\text { From final diagnosis up } \\
\text { to surgery }\end{array}$ & 17.8 & \pm 18.2 & 14 & 3 & 130 \\
$\begin{array}{l}\text { From surgery up to } \\
\text { adjuvant chemotherapy } \\
\text { radiotherapy }\end{array}$ & 31.05 & \pm 33.9 & 21 & 15 & 180 \\
\hline
\end{tabular}

Among the respondents $44.7 \%$ were detected by breast related sign and symptoms, $29.3 \%$ had incidental findings and $19.3 \%$ noticed their problem by self breast examination (Fig. 2).

\section{Detection of breast cancer by patient}

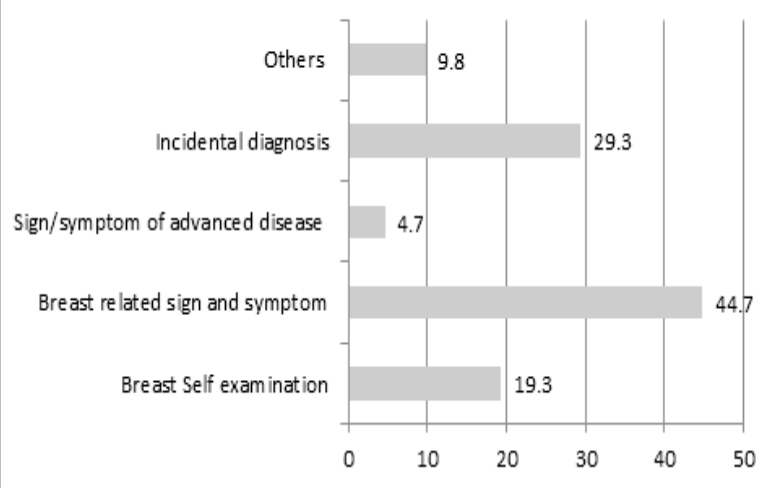

Figure 2: Distribution of the respondents by detection of breast cancer patient

Table IV: Total delay up to surgery and until receiving adjuvant chemotherapy or radiotherapy (in days)

\begin{tabular}{llllll}
$\begin{array}{l}\text { Time elapsed from up } \\
\text { to attending medical care }\end{array}$ & Mean SD & Median & Min & Max \\
\hline $\begin{array}{l}\text { Total time from } \\
\text { appearance of } \\
\text { symptom to surgery }\end{array}$ & 114.3 & \pm 53.3 & 117.5 & 31 & 254 \\
$\begin{array}{l}\text { Total time from } \\
\text { appearance of } \\
\text { symptom to start }\end{array}$ & $151.2 \pm 62.8$ & 124.0 & 51 & 310 \\
$\begin{array}{l}\text { adjuvant chemotherapy/ } \\
\text { radiotherapy }\end{array}$ & & & & & \\
\hline
\end{tabular}

Of them $53.8 \%$ had lack of awareness, $38.9 \%$ had delay due to lack of money, $21.7 \%$ had to long wait for surgery and $14.2 \%$ patient were reluctant (Fig. 3).

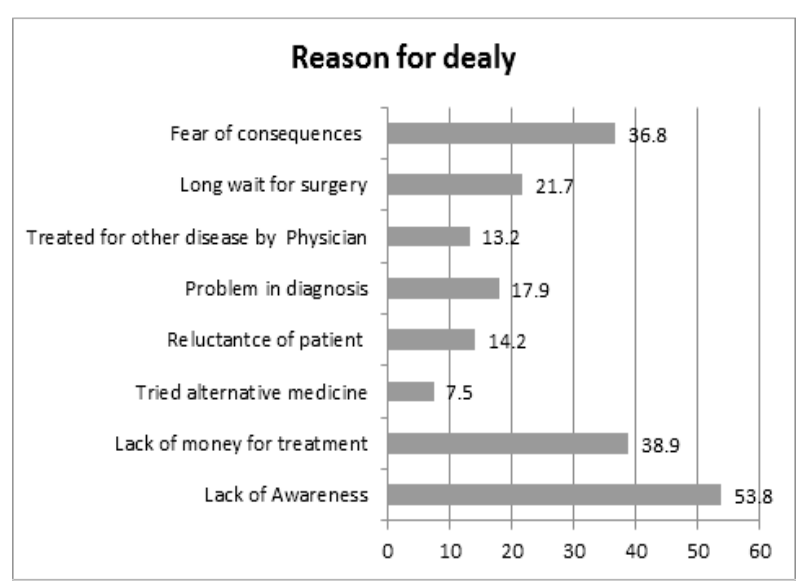

Figure 3: Distribution of the respondents by reasons for delay.

Table V: Comparison of total delay in different stages of breast cancer in days.

\begin{tabular}{|c|c|c|c|c|c|}
\hline & & $\begin{array}{l}\text { Stage I + } \\
\text { Stage II }\end{array}$ & $\begin{array}{l}\text { Stage III+ } \\
\text { Stage IV }\end{array}$ & $\mathbf{t}$ & $p$ value \\
\hline \multirow{2}{*}{$\begin{array}{l}\text { Time elapsed from } \\
\text { first symptom to } \\
\text { surgery }\end{array}$} & Mean & 87.89 & 115.06 & \multirow{2}{*}{\multicolumn{2}{|c|}{3.120 .038}} \\
\hline & SD & 48.21 & 45.05 & & \\
\hline \multirow{2}{*}{$\begin{array}{l}\text { Time from first } \\
\text { symptom to } \\
\text { Chemotherapy } \\
\text { or radiotherapy }\end{array}$} & Mean & 119.63 & 162.62 & \multirow[b]{2}{*}{2.56} & \\
\hline & SD & 58.33 & 84.77 & & 0.013 \\
\hline
\end{tabular}

\section{Discussion:}

Delay in treatment however, is generally related to the health system, especially in developing countries, where prevails limited availability of specific cancer centers. In Bangladesh only thirteen medical colleges and two private institutes have Radiotherapy Department. Liner accelerator is present in only three public (Dhaka Medical College Hospital, National Institute of Cancer research and Hospital and Bogura Medical College Hospital) and two private institutes. There is little private cancer hospital in the country. These are the only facilities for 150 million populations, hence long sequelae and fierce competetion in accessing such care is a common phenomenon. Absence of effective health insurance and lower socioeconomic status of patients, long delays for surgery and adjuvant therapy are not rare? 
In the developed country age of incidence in breast cancer is after 50 years ${ }^{10}$. But in our study majority of the breast cancer patients were in between 35 to 45 years of age (mean age $40.6 \pm 59$ ).

After the diagnosis is established, one may speculate that the length of the interval from the biopsy to the surgery and from surgery to adjuvant chemotherapy may influence survival. Since radiotherapy is generally applied after chemotherapy, an initial delay may also cause a further delay in radiotherapy, which may again compromise local control and even probably survival ${ }^{11}$.

Health seeking is a rare event in poor country like Bangladesh, particularly women are even more deprived, and hence it is rather not surprising that disease of women will suffer some degree of delay. However if an active screening system is available, most people would have been detected earlier which definitely have impact on delay and survival eventually.

Another important determinant is the popularity of village doctors. In our data around $43.4 \%$ went to village doctors, $11.3 \%$ visited to Kobiraj, and 9.4\% went to homeopath. This group is mostly with no recognized expertise training, hence their subnormal clinical capacity misses diagnosis like cancer and they treat the patients until the patients develop a situation that require obvious higher level of treatment. The retention of patient by unqualified provider significantly increases the delay ${ }^{12}$. Self-examination could be a significant issue of early diagnosis advocacy in our study. Subjects only $19.3 \%$ noticed the breast abnormality while doing self-examination, $44.7 \%$ noticed breast abnormality as a result of breast related sign and symptoms, $4.7 \%$ had sign and symptoms of advanced disease and 29\% were diagnosed incidentally.

In the current study delay was assessed in five stages. Average delay occurred from development of first symptom to attending traditional or unqualified provider was $38.1 \pm 25.7$ days. The transition from unqualified provider to qualified medical personnel was $31.9 \pm 35.05$ days. The time taken by medical personnel to establish the diagnosis through histopathology was $12.5 \pm 7.0$ days thereafter to perform surgery after diagnosis it took $17.8 \pm 18.13$ days. After surgery another $31.05 \pm 33.84$ days were needed to start adjuvant chemotherapy or radiotherapy. Physicians try different options of treatment, sometimes patient change doctors due to dissatisfaction, all these contribute to delay.

Mean total time lapsed from appearance of symptom to perform surgery among breast cancer patients was $114.25 \pm 53.24$ days with a median delay of 117.5 days. Mean total time lapsed from appearance of symptom to have chemotherapy or radiotherapy among breast cancer patients was $151.15 \pm 62.82$ days with a median delay of 124 days. Raysonet $\mathrm{al}^{13}$ found that 91 days time elapsed from detection of the disease to start first adjuvant therapy. Our median delay (124 days) to start adjuvant therapy is more than those findings because of lack of money for treatment and fear to take adjuvant therapy.

Facione et $\mathrm{al}^{5}$ showed lower income, lower educational level, experienced prejudice in care delivery, lack of access to health care, fatalism about breast cancer, poor health care utilization habits, self-care behavior, spouse/partner and employer perceived constraints, lack of knowledge of breast cancer's presenting symptoms were associated with delay. Our study also made an attempt to explore the possible reason for the delay in general. The reasons were lack of awareness, lack of money for treatment, fear of consequences and lack of access of health care facility that is comparable to that study.

In a study from Turkey ${ }^{14}$ median delay was 7.5 days to surgery, but this study revealed about 14 days of median delay for surgery. Time elapsed after biopsy to surgery more in this study due to delay in admission in hospital and then long waiting period for surgery.

In a study from Japan, a significant difference of disease free survival was observed between the groups of patients operated within 7 days after biopsy and longer than 8 days (delay group) favoring prompt surgery as soon as possible. Authors concluded that the acceptable delay between biopsy and mastectomy was only 7 days and longer delays were harmful ${ }^{9}$. On the contrary; a study from Denmark looking into the impact of patient and doctor delay found that prognosis was inferior in presence of patient delay but superior in doctor delay ${ }^{14}$.

\section{Conclusion:}

The average delay in seeking treatment to have surgery after diagnosis is around 4 months and to have chemotherapy is 5 months, most delay occurs during the time from development of first symptom to attending traditional health care provider. The time taken by medical personnel to establish the diagnosis through histopathology was around another $10-15$ days thereafter to perform surgery after diagnosis it took another 2 to 3 week days. After surgery another 4 to 5 weeks were lapsed to start adjuvant chemotherapy or radiotherapy. The major cause of delay identified was lack of awareness (53.8\%), lack of money for treatment $(38.9 \%)$, in $36.8 \%$ cases patient herself made the delay due to fear of consequences of the disease or treatment and in around $22 \%$ cases delay occurred due to long wait for surgery. Patients with stages III \& IV were found to have significantly more total delay than stages I \& II diseases $(\mathrm{p}<.05)$. 


\section{Limitation:}

Researcher had following limitation during this study: 1. Current study was a cross sectional study, issue like patient delay in diagnosis of breast tumour, particularly in the private part requires more stringent study design to explore possible factors.

2. Sample size of the study was small and was reduced purposively (by reducing precision level) accordingly to researcher's convenience, which might also affect the study findings.

\section{Recommendations:}

As patients own social stigma, shyness, negligence or practices which are the major contributor to the total delay in treatment, awareness raising campaign that address breast cancer warning signs should be helpful. Increased number of facility and experts can reduce the provider's delay.

\section{References :}

1. Afzelius P, Zedeler K, Sommer H, Mouridsen HT, Blichert-Toft M. Patient's and doctor's delay in primary breast cancer. Prognostic implications. Acta Oncol. 1994; 33:345-51.

2. Jensen AR, Nellemann HM, Overgaard J.Tumor progression in waiting time for radiotherapy in breast cancer. Radiother Oncol. 2007; 84:5-10.

3. Richards MA, Westcombe AM, Love SB, Littlejohns P, Ramirez AJ. Influence of delay on survival in patients with breast cancer: a systematic review. Lancet 1999; 353:1119-26.

4. Love DR. Hope for breast cancer in Bangladesh. Available from the web http://dhaka.usembassy.gov/uploads/images/RVRAbXXI8 SGTMhP8fKz8w/pre1jun26_06.pdf acessed on 20/8/09.

5. Facione NC. Delay versus help seeking for breast cancer symptoms. A critical review of the literature on patient and provider delay. Soc Sci Med.1993; 36:1521-34.

6. Hebert-Croteau N, Freeman CR, Latreille J, Brisson J. Delay in adjuvant radiation treatment and outcomes of breast cancer- a review. Breast Cancer Respondent Treat 2002;74:77-80.

7. Charlson ME. Delay in the treatment of carcinoma of the breast. Surg Gynecol Obstet. 1985; 160:393-99.

8. Machiavelli M, Leone B, Romero A, Perez J,Vallejo C,Bianco A, et al. Relation between delay and survival in 596 patients with breast cancer. Oncology 1989; 49:78-82American Cancer Society.Breast Cancer Facts and Figures 20052006.Retrieved,Apr.16,2007.

9. Dohrmann PJ, Hughes ESR, McDermott F, Price A. Symptom duration, tumor staging and survival in patients with carcinoma of the breast. Surg Gynecol Obstet. 1982; 154:707-10.

10. "World Cancer Report". International Agency for Research on Cancer. June 2003.World-Cancer-Report. Retrieved 2009-03-26.

11. Fact sheet No. 297: Cancer". World Health Organization. February 2006. http://www.who.int/mediacentre/factsheets/fs297/ en/index.html. Retrieved 2009-03-26.
12. Facione NC, Miaskowski C, Dodd MJ, Paul SM.The SelfReported Likelihood of Patient Delay in Breast Cancer: New Thoughts for Early Detection. Preventive Medicine. 2002; 34(4):397-407.

13. Rayson D,Chiasson D, Dewar R. Elapsed time from breast cancer detection to first adjuvant therapy in Canadian provience.CMAJ 2004; 170(6):957-61.

14. Samur M, Bozruk HS, Dalmaz G, Karaveli S. Treatment delay in breast cancer;does it really have an impact on prognosis.Turk $\mathrm{J}$ cancer 2002; 32(4):138-47. 